\title{
Coupling Dynamic Behavior Characteristics of a Spacecraft Beam with Composite Laminated Structures and Large-Scale Motions
}

\author{
Bindi You $\mathbb{D}^{D}$, Zhihui Gao, Jianmin Wen $(\mathbb{D}$, Yiming Sun, Peibo Hao, and Dong Liang \\ School of Naval Architecture and Ocean Engineering, Harbin Institute of Technology, Weihai 264209, China \\ Correspondence should be addressed to Jianmin Wen; wenjm@hitwh.edu.cn
}

Received 27 May 2017; Revised 10 October 2017; Accepted 11 October 2017; Published 11 March 2018

Academic Editor: Nicolas Avdelidis

Copyright (c) 2018 Bindi You et al. This is an open access article distributed under the Creative Commons Attribution License, which permits unrestricted use, distribution, and reproduction in any medium, provided the original work is properly cited.

\begin{abstract}
A nonlinear dynamic modeling method for a spacecraft body composed of a laminated composite beam undergoing large rotation is proposed in this paper. To study the characteristics of a laminated composite beam attached to a spacecraft body for the dynamic systems, the deformation description of a laminated beam is established with the consideration of laying angles and laying layers, and the displacement-strain relations is acquired based on the global-local higher-order shear deformation theory. Accordingly, a nonlinear dynamic model of the spacecraft body composed of a laminated composite beam is deduced using Hamilton variational principle. And the complete coupling terms for the laminated material properties are considered unlike any other singular or unidirectional materials. Then, the dynamic behavior of the spacecraft system is analyzed by comparison of an orthogonalsymmetric, singular, and unidirectional laminated beam. The results show that the laminated composite structures have significant influences on the dynamics properties of spacecraft compared with conventional equivalent singular or unidirectional materials. Hence, the nonlinear model is well suitable for approaching the problem of coupling relationship between geometric nonlinearity and large rotation motions. These conclusions will have significant theory and engineering practice values for coupling dynamics properties of laminated beams.
\end{abstract}

\section{Introduction}

Laminated composite materials are formed by combining layers of different materials or the same material by using different laying angles, laying sequence, and laying layers [1-3]. Some of the properties can be improved by forming a composite material. For example, the stiffness and strength of fibrous composites come from fibers which are stiffer and stronger than the same material in bulk form [4]. In addition, some new laminated structures composed of different reinforcements were investigated in $[5,6]$, such as basalt fiber reinforced polymer and carbon fiber reinforced polymer composites. However, stiffness changes during the service loading of composite laminates can be significantly large, especially as those changes affect deflections, dimensional changes, vibration characteristics, and load or stress distributions [7]. With the development of aerospace exploration technology, spacecraft is becoming so large-scale, complex, flexible, and lightweight that conventional alloy materials cannot meet the practical engineering needs. Because composite materials exhibit not only better strength and stiffness properties but also better fatigue life and vibration resistance. Some laminated structures formed by composite materials have been widely used in aviation, aerospace, and many other engineering fields [8].

Flexible beams undergoing large-scale motions have their own unique theoretical and practical values in many applications. Many slender structures in aerospace engineering, such as space manipulators, solar wings, and satellite antenna, can be idealized to beam structures, and the dynamics properties of those structures are critical to system performance, integrity, and reliability [9-11]. For these reasons, the dynamic behaviors of flexible bodies experiencing a large-scale motion have been studied by many researchers in some academic fields. Accordingly, a lot of research of multibody system dynamics modeling for beam structures has been presented. 
Space flexible beams with large-scale motion and nonlinear deformation have been studied in [12]. In particular, the effect of impact-induced damage on the mechanical behavior of laminated composite structures was studied in $[13,14]$. Rigid-flexible coupling system dynamic properties with large-scale translational motion were studied in [15]. Next, rigid-flexible coupling system dynamics properties of flexible beams with large-scale deformation were studied in [16]. However, the geometric nonlinearity of laminated structures with composite material has been studied by few researchers. Dynamic properties of rotating composite material plates were studied in [17]. And considering shear deformation, dynamics properties of rigid-flexible coupling composited material beam system were studied in [18]. Moreover, dynamics equations of laminated beams with a large-scale motion were presented in [19], and the influences on dynamics properties for the transverse shear deformation of laminated beams were analyzed. Then, the vibration properties of laminated beams were studied in [20]. However, the geometric nonlinear effect of deformations can significantly influence dynamic behavior of the spacecraft system within the framework of a multibody dynamics, and few researchers have illustrated the specific rigid-flexible coupling characteristics of the laminated composite structures. Moreover, most of the above researchers did not consider the influence of laminated composite material beams on its own dynamics properties with large-scale motion. Thus, how to reasonably derive exact models for a rotating laminated beam attached to a spacecraft body within the context of multibody system dynamics has been a subject of several researches.

In order to study dynamic behavior characteristics of a spacecraft beam with laminated composite structures and a large-scale motion, the aim of the present investigation is to develop a dynamic model. Also, the rigid-flexible coupling dynamics modeling are performed with the consideration of laying angles and laying layers of laminated composite beams. Then, the complete expressions of nonlinear terms, coupled deformation terms, and nonlinear elastic forces are developed in this study.

\section{Formulation for a Laminated Composite Beam with a Large-Scale Motion}

2.1. Deformation Description. The laminated composite beam can be illustrated in Figure 1. The length, width, and height of the beam are denoted as $a, b$, and $h(b \ll a, h \ll a)$. The laminated beam is composed of $L$ orthotropic layers. $\left(O_{0}, e^{(0)}\right)$ and $(O, e)$ are the inertial reference coordinate system and floating coordinate system, respectively. When the laminated composite beam undergoes a large-scale motion with a spacecraft body, the deformation relative to the floating coordinate system will be produced in the laminated beam. An arbitrary point of the laminated composite beam can move from position $P_{0}$ before deformation to position $P$ after deformation, and the displacement vector can be expressed as $\mathbf{u}$. In Figure $1, \boldsymbol{\rho}$ and $\boldsymbol{\rho}_{0}$ denote displacement vectors of points $P$ and $P_{0}$ relative to floating coordinate origin $O$ of the laminated composite beam, $\mathbf{r}_{0}$ and $\mathbf{r}$ denote displacement vectors of points $O$ and $P$ relative to inertial reference coordinate origin $O_{0} . z_{k}$ is the coordinate value of the $k$ th layer in the direction of $e_{3}$, and $h_{k}$ is the lamina thickness of the $k$ th layer by $h_{k}=z_{k+1}-z_{k}$. In the inertial reference coordinate system $\left(\mathrm{O}_{0}, e^{(0)}\right)$, the position vector $\mathbf{r}$ of point $P$ of the laminated composite beam can be expressed as

$$
\mathbf{r}=\mathbf{r}_{0}+\rho=\mathbf{r}_{0}+\mathbf{A}\left(\rho_{0}+\mathbf{u}\right)
$$

where $\mathbf{A}$ is the direction cosine matrix between the floating coordinate system $(O, e)$ and inertial reference coordinate system $\left(\mathrm{O}_{0}, e^{(0)}\right)$.

Let $\mathbf{u}^{(k)}=\left[u^{(k)} v^{(k)} w^{(k)}\right]$ be the deformation of a point $P_{0}{ }^{(k)}$ on the mid-plane of the layer relative to floating coordinate system, based on the global-local higher-order shear deformation theory, then the deformations $u^{(k)}, v^{(k)}$, and $w^{(k)}$ (in Figure 2) of any point on the $k$ th layer of the laminated composite beam can be expressed as [21]

$$
\begin{aligned}
& u^{(k)}=u_{0}^{(k)}+z \varphi_{x}^{(k)}-c_{1} z^{3}\left(\varphi_{x}^{(k)}+\frac{\partial w_{0}^{(k)}}{\partial x}\right), \\
& v^{(k)}=v_{0}^{(k)}+z \varphi_{y}^{(k)}-c_{1} z^{3}\left(\varphi_{y}^{(k)}+\frac{\partial w_{0}^{(k)}}{\partial y}\right), \\
& w^{(k)}=w_{0}^{(k)},
\end{aligned}
$$

where $c_{1}=4 / 3 h^{2}, \varphi_{x}=\partial u / \partial z, \varphi_{y}=\partial v / \partial z, u_{0}{ }^{(k)}, v_{0}{ }^{(k)}$, and $w_{0}{ }^{(k)}$ are the displacements on the mid-plane of the $k$ th layer of the laminated composite beam, and $z$ is far away from the mid-plane of laminated composite beam as shown in Figure 2.

The laying angles are denoted as $\theta^{(k)}, k=1,2, \ldots, L$, in the laminated composite beam as shown in Figure 3 . Then, the total deformation vector of the laminated composite beam can be written as

$\mathbf{u}=\mathbf{u}^{(1)}+\cdots+\mathbf{u}^{(k)}+\cdots+\mathbf{u}^{(L)}=\sum_{k=1}^{L} \mathbf{B}^{(k)} \mathbf{u}^{(k)}, \quad k=1,2, \ldots, L$,

where $\mathbf{u}^{(k)}$ is the position vector of any point on the mid-plane of the $k$ th layer, $\mathbf{B}^{(k)}$ is the direction cosine transformation matrix from floating coordinate system $(O, e)$ of the $k$ th layer (shown in Figure 3 ) to inertial reference coordinate system $\left(\mathrm{O}_{0}, e^{(0)}\right)$, and

$$
\mathbf{B}^{(k)}=\left[\begin{array}{ccc}
\cos \theta^{(k)} & -\sin \theta^{(k)} & 0 \\
\sin \theta^{(k)} & \cos \theta^{(k)} & 0 \\
0 & 0 & 1
\end{array}\right] .
$$

The transformation relations between Euler parameters and Euler angles can be written as 


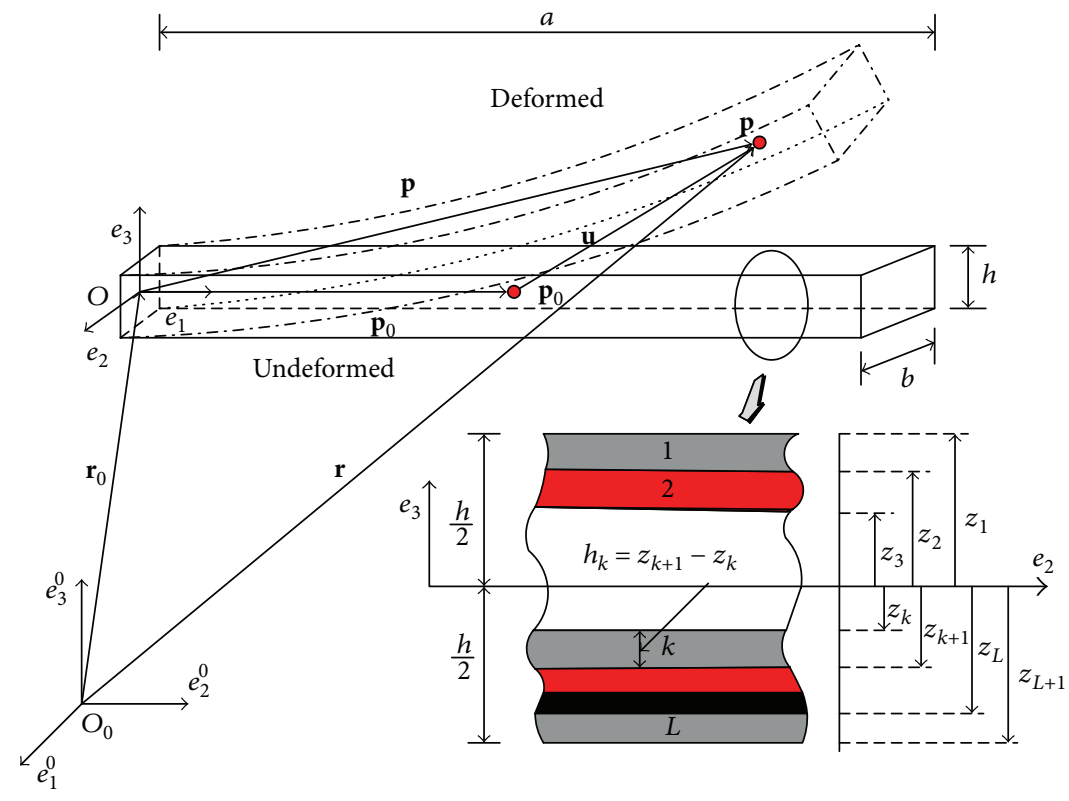

Figure 1: Laminated beam with a large-scale motion.

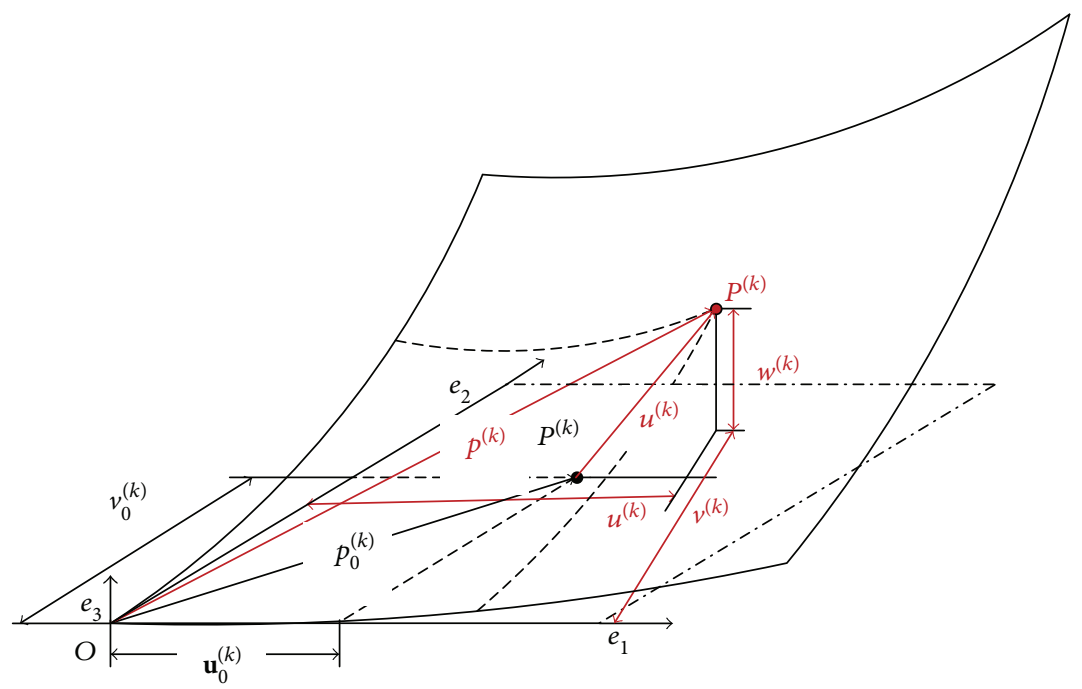

Figure 2: Deformation of the $k$ th layer of laminated composite beam.

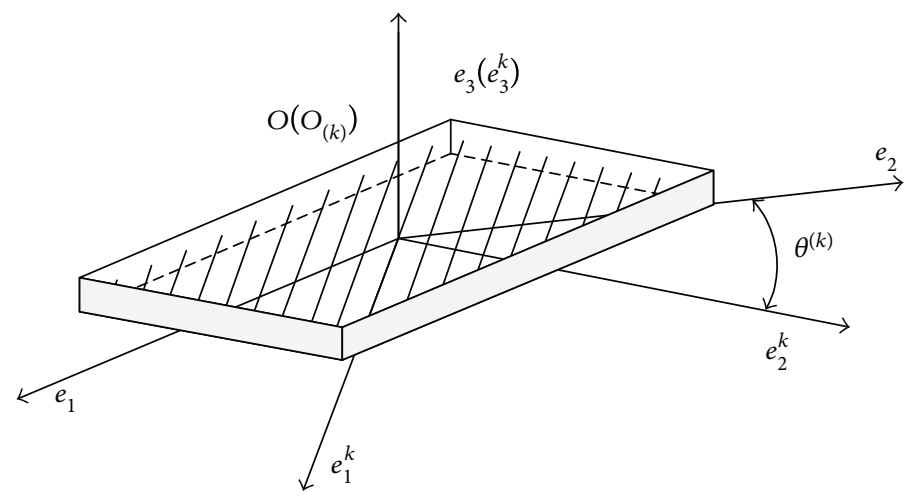

Figure 3: Laying angles of the $k$ th layer of a laminated composite beam. 


$$
\begin{aligned}
& \Theta_{0}=\cos \frac{\psi}{2} \cos \left(\frac{\vartheta+\varphi}{2}\right), \\
& \Theta_{1}=\sin \frac{\psi}{2} \cos \left(\frac{\vartheta-\varphi}{2}\right), \\
& \Theta_{2}=\sin \frac{\psi}{2} \sin \left(\frac{\vartheta-\varphi}{2}\right), \\
& \Theta_{3}=\cos \frac{\psi}{2} \sin \left(\frac{\vartheta+\varphi}{2}\right),
\end{aligned}
$$

where $\psi, \vartheta$, and $\varphi$ are the relative rotating angles of $(O, e)$ around $e_{3}{ }^{(0)}, e_{1}{ }^{(0)}$, and $e_{2}{ }^{(0)}$ of $\left(O_{0}, e^{(0)}\right)$, respectively.

We introduce a $3 \times 4$ order auxiliary matrix $\widehat{\mathbf{G}}$ defined by

$$
\widehat{\mathbf{G}}=\left[-\boldsymbol{\Theta}-\tilde{\boldsymbol{\Theta}}+\Theta_{0} \mathbf{I}\right]=\left[\begin{array}{cccc}
-\Theta_{1} & \Theta_{0} & \Theta_{3} & -\Theta_{2} \\
-\Theta_{2} & -\Theta_{3} & \Theta_{0} & \Theta_{1} \\
-\Theta_{3} & -\Theta_{2} & -\Theta_{1} & \Theta_{0}
\end{array}\right],
$$

where $\Theta=\left[\Theta_{1}, \Theta_{2}, \Theta_{3}\right]^{\mathrm{T}}$ and antisymmetric matrix

$$
\tilde{\Theta}=\left[\begin{array}{ccc}
0 & -\Theta_{3} & \Theta_{2} \\
\Theta_{3} & 0 & -\Theta_{1} \\
-\Theta_{2} & \Theta_{1} & 0
\end{array}\right]
$$

Substituting (2), (3), (5), and (6) into (1), then differentiating with respect to time $t$, we have the velocity vector $\dot{\mathbf{r}}$ of an arbitrary point $P$ in $\left(O_{0}, e^{(0)}\right)$ :

$$
\dot{\mathbf{r}}=\left[\begin{array}{lll}
\mathbf{I} & -\mathbf{A} \tilde{\rho} & \mathbf{A}
\end{array}\right]\left[\begin{array}{c}
\dot{\mathbf{r}}_{\mathbf{0}} \\
\boldsymbol{\omega}^{\prime} \\
\sum_{k=1}^{L} \mathbf{B}^{(k)} \dot{\mathbf{u}}^{(k)}
\end{array}\right], \quad k=1,2, \ldots, L,
$$

where $\tilde{\boldsymbol{\rho}}$ is the antisymmetric matrix,

$$
\tilde{\boldsymbol{\rho}}=\left[\begin{array}{ccc}
0 & -z & y \\
z & 0 & x \\
-y & x & 0
\end{array}\right]
$$

and $x, y$, and $z$ are the displacement coordinates of point $P_{0}$ along axis $e_{1}, e_{2}$, and $e_{3}$, respectively, in Figures 2 and 3. We introduce a four-dimension vector $\Lambda$ defined by $\Lambda=$ $\left[\Theta_{0} \Theta_{1} \Theta_{2} \Theta_{3}\right]^{\mathrm{T}}$, and $\boldsymbol{\omega}^{\prime}=2 \widehat{\mathbf{G}} \dot{\boldsymbol{\Lambda}}$ in (8).

Using the finite element discretization method, the laminated composite beam can be divided into $n$ spatial beam elements having two nodes as shown in Figure 4, in which each node has six deformation degrees of freedom.

The node displacement vector $\underline{\mathbf{q}}_{k}$ of the spatial beam element $i$ in the local reference coordinate system $\left(O_{i}, e^{(i)}\right)$ can be written as

$$
\underline{\mathbf{q}}_{k}=\left[\mathbf{q}_{i} \mathbf{q}_{i+1}\right]^{\mathrm{T}},
$$

where

$$
\mathbf{q}_{k}=\left[\begin{array}{llllll}
u_{k} & v_{k} & w_{k} & \gamma_{x k} & \gamma_{y k} & \gamma_{z k}
\end{array}\right]^{\mathrm{T}}, \quad k=i, i+1 .
$$

A simple way to obtain the derivatives of the director field is to use interpolation. So, being $N_{j}(j=1,2, \ldots, 6)$, linear Lagrangian shape function coefficients will be used. Then, the deformation vector $\mathbf{u}_{i}$ of the spatial beam element $i$ in $\left(O_{i}, e^{(i)}\right)$ can be written as

$$
\mathbf{u}_{i}=\mathbf{N q}_{k},
$$

where $\mathbf{N}$ is the shape function of the spatial beam element $i$ with two nodes and six degrees of freedom of two nodes defined by [22]

$$
\mathbf{N}=\left[\begin{array}{llll}
\mathbf{N}_{x} & \mathbf{N}_{y} & \mathbf{N}_{z} & \mathbf{N}_{\gamma}
\end{array}\right]^{\mathrm{T}}=\left[\begin{array}{cccccccccccc}
N_{1} & 0 & 0 & 0 & 0 & 0 & N_{2} & 0 & 0 & 0 & 0 & 0 \\
0 & N_{2} & 0 & 0 & 0 & N_{4} & 0 & N_{5} & 0 & 0 & 0 & N_{6} \\
0 & 0 & N_{3} & 0 & -N_{4} & 0 & 0 & 0 & N_{5} & 0 & -N_{6} & 0 \\
0 & 0 & 0 & N_{1} & 0 & 0 & 0 & 0 & 0 & N_{2} & 0 & 0
\end{array}\right] .
$$

The parameters of $\mathbf{N}$ can be written as

$$
\begin{aligned}
& N_{1}=1-\tau, \\
& N_{2}=\tau, \\
& N_{3}=1-3 \tau^{2}+2 \tau^{3}, \\
& N_{4}=\tau l_{i}(1-\tau)^{2}, \\
& N_{5}=3 \tau^{2}-2 \tau^{3}, \\
& N_{6}=\tau^{2} l_{i}(\tau-1),
\end{aligned}
$$

where $\tau=\underline{x} / l_{i}$, and $\underline{x}$ is the total displacement coordinates of point $P$ along axis $e_{1}$ in $\left(O_{i}, e^{(i)}\right), l_{i}$ is the length of the spatial beam element $i$.

The node deformation displacement vector $\mathbf{q}$ in $(O, e)$ can be given by

$\underline{\mathbf{q}}=\underline{\mathbf{q}}_{k}+\left[\begin{array}{llllllllllll}u_{i} & v_{i} & w_{i} & 0 & 0 & 0 & u_{i} & v_{i} & w_{i} & 0 & 0 & 0\end{array}\right]^{\mathrm{T}}$. 


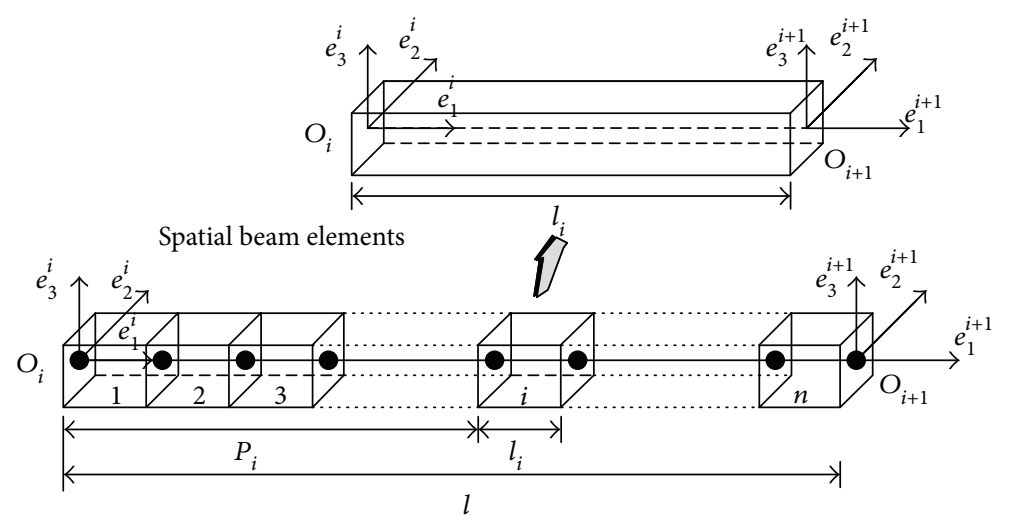

FIGURE 4: Element division of a laminated composite beam.

We introduce a $12 \times 12$ order orientation matrix $\underline{\mathbf{B}}^{k}$ based on nodes of spatial beam element, and it can be defined by [22]

$$
\underline{\mathbf{B}}^{k}=\left[\begin{array}{cc}
0 & \mathbf{I}_{6 \times 6} \\
0 & 0
\end{array}\right]_{12 \times 12} .
$$

Then, the displacement vector of any point in $(O, e)$ can be given by

$$
\mathbf{u}_{i}=\left[\begin{array}{c}
\overline{\mathbf{N}}_{1} \underline{\mathbf{q}}-0.5 \underline{\mathbf{q}}^{\mathrm{T}} \mathbf{H q} \underline{\mathbf{q}} \\
\overline{\mathbf{N}}_{2} \underline{\mathbf{q}} \\
\overline{\mathbf{N}}_{3} \underline{\mathbf{q}}
\end{array}\right]=\boldsymbol{\Phi} \underline{\mathbf{q}},
$$

where $\overline{\mathbf{N}}_{j}(j=1,2,3)$ is a $1 \times 12$ order matrix, $\overline{\mathbf{N}}_{1}=\mathbf{N}_{x} \underline{\mathbf{B}}^{k}$, $\overline{\mathbf{N}}_{2}=\mathbf{N}_{y} \underline{\mathbf{B}}^{k}, \overline{\mathbf{N}}_{3}=\mathbf{N}_{z} \underline{\mathbf{B}}^{k}$, and $\mathbf{H}$ is a coupled shape function matrix of order $12 \times 12$.

$$
\Phi=\left[\begin{array}{c}
\overline{\mathbf{N}}_{1} \underline{\mathbf{q}}-0.5 \underline{\mathbf{q}}^{\mathrm{T}} \mathbf{H} \underline{\mathbf{q}} \\
\overline{\mathbf{N}}_{2} \underline{\mathbf{q}} \\
\overline{\mathbf{N}}_{3} \underline{\mathbf{q}}
\end{array}\right] .
$$

The coupled shape function matrix $\mathbf{H}$ can be written as

$$
\mathbf{H}=\int_{0}^{\underline{x}}\left(\frac{\partial \overline{\mathbf{N}}_{1}^{\mathrm{T}}}{\partial \underline{x}}\right)\left(\frac{\partial \overline{\mathbf{N}}_{1}}{\partial \underline{x}}\right) \mathrm{d} \underline{x}+\int_{0}^{\underline{x}}\left(\frac{\partial \overline{\mathbf{N}}_{2}^{\mathrm{T}}}{\partial \underline{x}}\right)\left(\frac{\partial \overline{\mathbf{N}}_{2}}{\partial \underline{x}}\right) \mathrm{d} \underline{x} .
$$

2.2. Displacement-Stress Equations of a Laminated Composite Beam. According to the deformation displacement of point $P$ in (2) and the displacement-strain relations of elastic mechanics based on the global-local higher order shear deformation theory, the strain of a laminated composite beam can be given by [19]

$$
\begin{aligned}
& \varepsilon_{x x}=\frac{\partial u_{0}}{\partial x}+\frac{1}{2}\left(\frac{\partial w_{0}}{\partial x}\right)^{2}+z \frac{\partial \varphi_{x}}{\partial x}-c_{1} z^{3}\left(\frac{\partial \varphi_{x}}{\partial x}+\frac{\partial^{2} w_{0}}{\partial x^{2}}\right), \\
& \varepsilon_{y y}=\frac{\partial v_{0}}{\partial y}+\frac{1}{2}\left(\frac{\partial w_{0}}{\partial y}\right)^{2}+z \frac{\partial \varphi_{y}}{\partial y}-c_{1} z^{3}\left(\frac{\partial \varphi_{y}}{\partial y}+\frac{\partial^{2} w_{0}}{\partial y^{2}}\right),
\end{aligned}
$$

$$
\begin{aligned}
\varepsilon_{z z}= & 0, \\
\gamma_{x y}= & \frac{\partial u_{0}}{\partial y}+\frac{\partial v_{0}}{\partial x}+\frac{\partial w_{0}}{\partial x} \frac{\partial w_{0}}{\partial y}+z\left(\frac{\partial \varphi_{x}}{\partial y}+\frac{\partial \varphi_{y}}{\partial x}\right) \\
& -c_{1} z^{3}\left(\frac{\partial \varphi_{x}}{\partial y}+\frac{\partial \varphi_{y}}{\partial x}+2 \frac{\partial^{2} w_{0}}{\partial x \partial y}\right), \\
\gamma_{y z}= & \varphi_{y}+\frac{\partial w_{0}}{\partial y}-c_{2} z^{2}\left(\varphi_{y}+\frac{\partial w_{0}}{\partial y}\right), \\
\gamma_{x z}= & \varphi_{x}+\frac{\partial w_{0}}{\partial x}-c_{2} z^{2}\left(\varphi_{x}+\frac{\partial w_{0}}{\partial x}\right) .
\end{aligned}
$$

Using the displacement-strain relations of (20), the displacement-strain equation of the $k$ th layer can be given by [19]

$$
\left\{\begin{array}{c}
\sigma_{x x} \\
\sigma_{y y} \\
\sigma_{z z} \\
\tau_{x y} \\
\tau_{y z} \\
\tau_{x z}
\end{array}\right\}_{k}=\left[\begin{array}{cccccc}
\bar{Q}_{11} & \bar{Q}_{12} & 0 & 0 & 0 & 0 \\
\bar{Q}_{12} & \bar{Q}_{22} & 0 & 0 & 0 & 0 \\
0 & 0 & 0 & 0 & 0 & 0 \\
0 & 0 & 0 & \bar{Q}_{66} & 0 & 0 \\
0 & 0 & 0 & 0 & \bar{Q}_{44} & 0 \\
0 & 0 & 0 & 0 & 0 & \bar{Q}_{55}
\end{array}\right]_{k}\left\{\begin{array}{c}
\varepsilon_{x x} \\
\varepsilon_{y y} \\
\varepsilon_{z z} \\
\gamma_{x y} \\
\gamma_{y z} \\
\gamma_{x z}
\end{array}\right\}_{k}
$$

where $Q_{i j}(i, j=1,2, \ldots, 6)$ is the equivalent stiffness coefficients of two-dimensional layers which can be defined by [21]

$$
\begin{aligned}
& \bar{Q}_{11}=Q_{11} n^{4}+2\left(Q_{12}+2 Q_{66}\right) m^{2} n^{2}+Q_{22} m^{4}, \\
& \bar{Q}_{12}=\left(Q_{11}+Q_{22}-4 Q_{66}\right) m^{2} n^{2}+Q_{12}\left(m^{4}+n^{4}\right), \\
& \bar{Q}_{22}=Q_{11} m^{4}+2\left(Q_{12}+2 Q_{66}\right) m^{2} n^{2}+Q_{22} n^{4}, \\
& \bar{Q}_{44}=\left(Q_{11}-Q_{12}-2 Q_{44}\right) m n^{3}+\left(Q_{12}-Q_{22}+Q_{44}\right) m^{3} n, \\
& \bar{Q}_{55}=\left(Q_{11}-Q_{12}-2 Q_{55}\right) m^{3} n+\left(Q_{12}-Q_{22}+Q_{55}\right) m n^{3}, \\
& \bar{Q}_{66}=\left(Q_{11}+Q_{22}-2 Q_{12}-2 Q_{66}\right) m^{2} n^{2}+Q_{66}\left(m^{4}+n^{4}\right),
\end{aligned}
$$

where $m=\sin \theta, n=\cos \theta$, and $\theta$ is the laying angle, and 


$$
\begin{aligned}
& Q_{11}=\frac{E_{1}}{1-v_{12} v_{21}}, \\
& Q_{12}=\frac{v_{12} E_{2}}{1-v_{12} v_{21}}, \\
& Q_{21}=\frac{v_{21} E_{2}}{1-v_{12} v_{21}}, \\
& Q_{22}=\frac{E_{2}}{1-v_{12} v_{21}}, \\
& Q_{66}=G_{12}, \\
& Q_{44}=G_{23}, \\
& Q_{55}=G_{13},
\end{aligned}
$$

where $v_{12}$ is the primary Poisson's ratio of a laminated composite beam, $v_{21}$ is the secondary Poisson's ratio, $E_{i}$ is the elastic modulus, and $G_{i j}$ is the shear modulus of elasticity.

We introduce the stress $\underline{\sigma}$ and the strain $\underline{\varepsilon}$ of point $P$ on the $k$ th layer of a laminated composite beam defined by

$$
\begin{aligned}
\underline{\sigma} & =\left[\begin{array}{llllll}
\sigma_{x x} & \sigma_{y y} & \sigma_{z z} & \tau_{x y} & \tau_{y z} & \tau_{x z}
\end{array}\right]_{k}^{\mathrm{T}}, \\
\underline{\varepsilon} & =\left[\begin{array}{llllll}
\varepsilon_{x x} & \varepsilon_{y y} & \varepsilon_{z z} & \gamma_{x y} & \gamma_{y z} & \gamma_{x z}
\end{array}\right]_{k}^{\mathrm{T}},
\end{aligned}
$$

Then, (21) can be rewritten as the matrix form

$$
\underline{\sigma}=\mathbf{Q} \underline{\varepsilon},
$$

where $\mathbf{Q}$ is reduced stiffness matrix of laminated composite beam along the primary fiber direction, and

$$
\mathbf{Q}=\left[\begin{array}{cccccc}
\bar{Q}_{11} & \bar{Q}_{12} & 0 & 0 & 0 & 0 \\
\bar{Q}_{12} & \bar{Q}_{22} & 0 & 0 & 0 & 0 \\
0 & 0 & 0 & 0 & 0 & 0 \\
0 & 0 & 0 & \bar{Q}_{66} & 0 & 0 \\
0 & 0 & 0 & 0 & \bar{Q}_{44} & 0 \\
0 & 0 & 0 & 0 & 0 & \bar{Q}_{55}
\end{array}\right]_{k}
$$

2.3. Rigid-Flexible Coupling Dynamics Modeling. The coupling dynamics equations of a laminated composite beam undergoing a large-scale motion can be obtained by using the Hamilton variational principle. The Hamilton variational principle can be given by [23]

$$
\int_{t_{1}}^{t_{2}}(\delta U-\delta T-\delta W) \mathrm{d} t=0
$$

where $T$ is the kinetic energy of the laminated composite beam, $U$ is the potential energy of the laminated composite beam, and $W$ is the virtual work by external forces of the laminated composite beam.

2.3.1. Kinetic Energy. The kinetic energy of the laminated composite beam undergoing a large-scale motion can be written as

$$
T=\frac{1}{2} \int_{V} \widehat{\rho} \dot{r}^{\mathrm{T}} \dot{r} \mathrm{~d} V
$$

where $\hat{\rho}$ is the mass density of the laminated composite beam, $V$ is the volume of the laminated composite beam, and $\dot{r}$ is the absolute velocity of any point of laminated composite beams.

According to (8) and (17), the velocity vector of point $P$ of the laminated beam in the inertial reference coordinate system $\left(\mathrm{O}_{0}, e^{(0)}\right)$ can be rewritten as

$$
\dot{\mathbf{r}}=\left[\begin{array}{lll}
\mathbf{I} & \mathbf{C} & \mathbf{D} \Phi
\end{array}\right]\left[\begin{array}{c}
\dot{\mathbf{r}}_{0} \\
\dot{\boldsymbol{\Lambda}} \\
\dot{\mathbf{q}}
\end{array}\right]=\mathbf{L} \dot{\mathbf{q}},
$$

where $\mathbf{C}=-2 \mathbf{A} \tilde{\boldsymbol{\rho}} \widehat{\mathbf{G}}$ and $\mathbf{D}$ is reduced transformation matrix, $\mathbf{D}=\mathbf{A} \sum_{k=1}^{L} \mathbf{B}^{(k)}(k=1,2, \ldots, L), \mathbf{L}=\left[\begin{array}{lll}\mathbf{I} & \mathbf{C} & \mathbf{D} \Phi\end{array}\right], \mathbf{q}$ is the generalized coordinate of the laminated composite beam, and $\mathbf{q}=\left[\begin{array}{lll}\mathbf{r}_{0}^{\mathrm{T}} & \boldsymbol{\Lambda}^{\mathrm{T}} & \underline{\mathbf{q}}^{\mathrm{T}}\end{array}\right]^{\mathrm{T}}$.

Substituting (29) into (28), the variational form of kinetic energy of the laminated composite beam can be given by

$$
\delta T=\frac{1}{2} \delta \dot{\mathbf{q}}^{\mathrm{T}} \mathbf{M} \delta \dot{\mathbf{q}}
$$

where $\mathbf{M}$ is the mass matrix of the laminated composite beam defined by

$$
\mathbf{M}=\left[\begin{array}{ccc}
m_{r r} & m_{r \theta} & m_{r d} \\
m_{\theta r} & m_{\theta \theta} & m_{\theta d} \\
m_{d r} & m_{d \theta} & m_{d d}
\end{array}\right]
$$

in which

$$
\begin{aligned}
& m_{r r}=\int_{v} \hat{\rho} \mathbf{I} \mathrm{d} V, \\
& m_{r d}=m_{d r}^{\mathrm{T}}=\int_{v} \hat{\rho} \mathbf{D} \boldsymbol{\Phi} \mathrm{d} V, \\
& m_{\theta \theta}=\int_{v} \hat{\rho} \mathbf{C}^{\mathrm{T}} \mathbf{C d} V, \\
& m_{\theta d}=m_{d \theta}^{\mathrm{T}}=\int_{v} \hat{\rho} \mathbf{C}^{\mathrm{T}} \mathbf{D} \boldsymbol{\Phi} \mathrm{d} V, \\
& m_{d d}=\int_{v} \hat{\rho} \boldsymbol{\Phi}^{\mathrm{T}} \mathbf{D}^{\mathrm{T}} \mathbf{D} \boldsymbol{\Phi} \mathrm{d} V, \\
& m_{r \theta}=m_{\theta r}^{\mathrm{T}}=\int_{v} \hat{\rho} \mathbf{C d} V .
\end{aligned}
$$

2.3.2. Potential Energy. The potential energy of the laminated composite beam undergoing a large-scale motion can be written as

$$
\delta \mathbf{U}=\frac{1}{2} \int_{V}\left(\underline{\sigma}^{\mathrm{T}} \delta \underline{\varepsilon}\right) \mathrm{d} V
$$


Further, we introduce a $6 \times 6$ order operator matrix $\underline{\hat{\mathbf{D}}}$ defined by

$$
\underline{\underline{\mathbf{D}}}=\left[\begin{array}{cccccc}
\frac{\partial}{\partial x} & 0 & \frac{1}{2}\left(\frac{\partial}{\partial x}\right)^{2}-c_{1} z^{3} \frac{\partial^{2}}{\partial x^{2}} & z \frac{\partial}{\partial x}-c_{1} z^{3} \frac{\partial}{\partial x} & 0 & 0 \\
0 & \frac{\partial}{\partial y} & \frac{1}{2}\left(\frac{\partial}{\partial y}\right)^{2}-c_{1} z^{3} \frac{\partial^{2}}{\partial y^{2}} & 0 & z \frac{\partial}{\partial y}-c_{1} z^{3} \frac{\partial}{\partial y} & 0 \\
0 & 0 & 0 & 0 & 0 & 0 \\
\frac{\partial}{\partial y} & \frac{\partial}{\partial x} & \frac{\partial}{\partial x} \frac{\partial}{\partial y}-c_{1} z^{3} 2 \frac{\partial^{2}}{\partial x \partial y} & \left(z-c_{1} z^{3}\right) \frac{\partial}{\partial y} & \left(z-c_{1} z^{3}\right) \frac{\partial}{\partial x} & 0 \\
0 & 0 & \left(1-c_{2} z^{2}\right) \frac{\partial}{\partial y} & 0 & \left(1-c_{2} z^{2}\right) & 0 \\
0 & 0 & \left(1-c_{2} z^{2}\right) \frac{\partial}{\partial x} & \left(1-c_{2} z^{2}\right) & 0 & 0
\end{array}\right] .
$$

Then, substituting (3), (17), (20), and (25) into (33), the potential energy of the laminated composite beam can be rewritten as

$$
\delta U=\frac{1}{2} \mathbf{q}^{\mathrm{T}} \mathbf{K} \delta \mathbf{q},
$$

where $\mathbf{K}$ is the stiffness matrix of the laminated composite beam defined by

$$
\mathbf{K}=\left[\begin{array}{ccc}
0 & 0 & 0 \\
0 & 0 & 0 \\
0 & 0 & \mathbf{k}_{f f}
\end{array}\right]
$$

where $\mathbf{k}_{f f}$ is a coupling stiffness matrix and

$$
\mathbf{k}_{f f}=\int_{V}\left(\underline{\widehat{\mathbf{B}}}^{\mathrm{T}} \underline{\widehat{\mathbf{D}}}^{\mathrm{T}} \mathbf{Q}^{\mathrm{T}} \underline{\widehat{\mathbf{D}}} \underline{\widehat{\mathbf{B}}}\right) \mathrm{d} V,
$$

in which $\underline{\widehat{\mathbf{B}}}=\sum_{k=1}^{L} \mathbf{B}^{(k)} \boldsymbol{\Phi}(k=1,2, \ldots, L)$. Consequently, $\mathbf{k}_{f f}$ is strongly determined by the constitutive relationships of laminated composite structure and a large rotation motion. In other words, as the beam structure is made of singular or unidirectional laminated materials, $\mathbf{k}_{f f}$ can be condensed statistically to a smaller sized matrix. Therefore, it accurately represents the nonlinear properties unlike other conventional stiffness matrix.

2.3.3. Virtual Work by External Forces. The virtual work $\delta W$ by external forces of the laminated composite beam with a large-scale motion can be written as

$$
\delta W=\delta W_{F}+\delta W^{*},
$$

where $\delta W^{*}$ is the virtual work by inertial forces and $\delta W_{F}$ is the virtual work by all the driving and disturbing forces.

Let the external force $\mathbf{F}$ act on the laminated composite beam; the virtual work by external forces can be given by

$$
\delta W_{F}=\mathbf{F}^{\mathrm{T}} \delta \mathbf{r}=\mathbf{F}^{\mathrm{T}}\left[\begin{array}{lll}
\mathbf{I} & \mathbf{C} & \mathbf{D} \boldsymbol{\Phi}
\end{array}\right]\left[\begin{array}{c}
\delta \mathbf{r}_{0} \\
\delta \boldsymbol{\Lambda} \\
\delta \underline{\mathbf{q}}
\end{array}\right]=\mathbf{F}_{q} \delta \mathbf{q}
$$

where $\mathbf{F}_{q}=\left[\begin{array}{lll}\mathbf{F}_{r} & \mathbf{F}_{\theta} & \mathbf{F}_{f}\end{array}\right], \mathbf{F}_{r}=\mathbf{F}^{\mathrm{T}}, \mathbf{F}_{\theta}=\mathbf{F}^{\mathrm{T}} \mathbf{C}$, and $\mathbf{F}_{f}=\mathbf{F}^{\mathrm{T}}$. DФ.

Given the generalized inertial force $\mathbf{F}^{*}$ acting on the laminated composite beam, the virtual work $\delta W^{*}$ by the inertial forces can be written as

$$
\delta W^{*}=\mathbf{F}^{*} \delta \mathbf{q},
$$

where $\mathbf{F}^{*}=\left[\begin{array}{lll}\mathbf{F}_{r}^{*} & \mathbf{F}_{\theta}^{*} & \mathbf{F}_{f}^{*}\end{array}\right]$. Accordingly,

$$
\begin{aligned}
& \mathbf{F}_{r}^{*}=-\mathbf{A}\left[4 \widehat{\mathbf{G}}\left(\mathbf{I}-\boldsymbol{\Lambda} \boldsymbol{\Lambda}^{\mathrm{T}}\right) \widehat{\mathbf{G}} \mathbf{S}_{t}+4 \widehat{\mathbf{G}}_{\dot{\hat{\mathbf{G}}}^{\mathrm{T}} \mathbf{S}}^{\mathbf{S q}}\right] \text {, } \\
& \mathbf{F}_{\theta}^{*}=-8 \dot{\widehat{\mathbf{G}}}^{\mathrm{T}} \boldsymbol{\Gamma}_{\theta \theta} \widehat{\mathbf{G}} \boldsymbol{\Lambda}-4 \dot{\widehat{\mathbf{G}}}^{\mathrm{T}} \boldsymbol{\Gamma}_{\theta f} \underline{\mathbf{q}}-2 \widehat{\mathbf{G}}^{\mathrm{T}} \boldsymbol{\Gamma}_{\theta \theta} \widehat{\mathbf{G}} \boldsymbol{\Lambda}, \\
& \mathbf{F}_{f}^{*}=-\int_{V} \widehat{\boldsymbol{\rho}}\left\{\boldsymbol{\Phi}^{\mathrm{T}}\left[4 \widehat{\mathbf{G}}\left(\mathbf{I}-\boldsymbol{\Lambda} \boldsymbol{\Lambda}^{\mathrm{T}}\right) \dot{\hat{\mathbf{G}} \boldsymbol{\rho}}+4 \widehat{\mathbf{G}} \dot{\hat{\mathbf{G}}}^{\mathrm{T}} \underline{\mathbf{q}}\right]\right\} \mathrm{d} V,
\end{aligned}
$$

where

$$
\begin{aligned}
\mathbf{S}_{t} & =\int_{V} \hat{\boldsymbol{\rho}} \boldsymbol{\rho} \mathrm{d} V, \\
\mathbf{S} & =\int_{V} \hat{\boldsymbol{\rho}} \boldsymbol{\Phi} \mathrm{d} V, \\
\boldsymbol{\Gamma}_{\theta \theta} & =\int_{V} \hat{\boldsymbol{\rho}} \tilde{\boldsymbol{\rho}}^{\mathrm{T}} \tilde{\boldsymbol{\rho}} \mathrm{d} V, \\
\boldsymbol{\Gamma}_{\theta f} & =\int_{V} \hat{\boldsymbol{\rho}} \tilde{\boldsymbol{\rho}} \boldsymbol{\Phi} \mathrm{d} V .
\end{aligned}
$$

Here, the expressions of $\mathbf{F}^{*}$ is characterized by more conciseness and formalized for the dynamic model, and it can be easily applied to the derivation of generalized force for arbitrary 


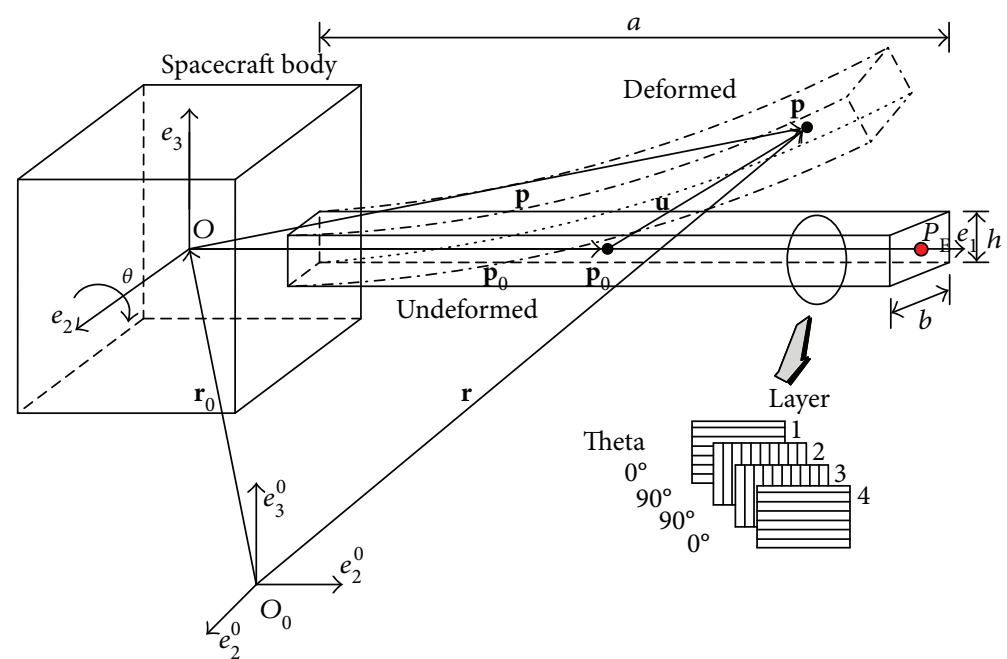

FIGURE 5: A spacecraft body with a laminated beam rotating around a fixed axis.

beam structures. Especially, in dealing with geometric nonlinear problems, the expressions can be used to avoid the derivation of large nonlinear stiffness matrix. Hence, it can significantly simplify the computational procedures.

Substituting (39) and (40) into (38), the virtual work $\delta W$ by external and inertial forces can be given by

$$
\delta W=\mathbf{F}_{q} \delta \mathbf{q}+\mathbf{F}^{*} \delta \mathbf{q}
$$

2.3.4. Coupling Dynamic Modeling of the Spacecraft System. Substituting (30), (35), and (43) into (27), the coupling dynamic equation of the laminated composite beam with a large-scale motion can be written as

$$
\left[\begin{array}{ccc}
\mathbf{M} & \mathbf{K} & \boldsymbol{\Phi}_{q}^{\mathrm{T}} \\
\boldsymbol{\Phi}_{q} & 0 & 0
\end{array}\right]\left[\begin{array}{l}
\ddot{\mathbf{q}} \\
\mathbf{q} \\
\lambda
\end{array}\right]=\left[\begin{array}{c}
\mathbf{F}_{q}+\mathbf{F}^{*} \\
\underline{\varsigma}
\end{array}\right],
$$

where $\lambda$ is the Lagrange multiplier, $\varsigma$ is the right-side term column matrix of the acceleration form constrain equation, and $\Phi_{q}$ is the Jacobi matrix of link hinge joints constrain equations of the spacecraft system.

\section{Numerical Simulations}

In this section, numerical simulations of a laminated composite beam rotating around the fixed axis are conducted as shown in Figure 5, including four laying layers and laying style $\left(0^{\circ} / 90^{\circ} / 90^{\circ} / 0^{\circ}\right)$. The size of the beam is $a \times$ $b \times h=1000.0 \mathrm{~mm} \times 10.0 \mathrm{~mm} \times 10.0 \mathrm{~mm}$, and the thickness of each layer $h_{k}=2.5 \mathrm{~mm}$. Point $P_{\mathrm{E}}$ is on the end of the laminated beam. The influences of gravity, air resistance force, and structural damping force have been neglected in this simulation.

The numerical examples can be governed and verified by a generally large-scale motion. The equation of angular displacement curve can be defined by
TABle 1: Material characteristic of boron/aluminum composite

\begin{tabular}{|c|c|c|}
\hline Parameters & Value & Note \\
\hline$E_{1}(\mathrm{GPa})$ & 215.3 & Modulus of elasticity along fiber direction 1 \\
\hline$E_{2}(\mathrm{GPa})$ & 144.1 & $\begin{array}{l}\text { Modulus of elasticity perpendicular to fiber } \\
\text { direction } 2\end{array}$ \\
\hline$E_{3}(\mathrm{GPa})$ & 144.1 & $\begin{array}{r}\text { Modulus of elasticity } \\
\text { direc }\end{array}$ \\
\hline$G_{12}(\mathrm{GPa})$ & 54.39 & Shear modulus along fiber directions 1 and 2 \\
\hline$G_{23}(\mathrm{GPa})$ & 54.39 & Shear modulus along fiber directions 2 and 3 \\
\hline$G_{13}(\mathrm{GPa})$ & 45.92 & Shear modulus along fiber directions 1 and 3 \\
\hline$\mu_{12}$ & 0.195 & Poisson's ratio along directions 1 and 2 \\
\hline$\mu_{23}$ & 0 & Poisson's ratio along directions 2 and 3 \\
\hline$\mu_{13}$ & 0.255 & Poisson's ratio along directions 1 and 3 \\
\hline
\end{tabular}
[24].

$$
\theta= \begin{cases}\frac{\Omega}{T} t-\frac{\Omega}{2 \pi} \sin \left(\frac{2 \pi}{T} t\right), & 0 \leq t \leq T, \\ \Omega, & t \geq T,\end{cases}
$$

where $\Omega=180^{\circ}$ and $T=20.0 \mathrm{~s}$.

Boron/aluminum composite materials are used in both the orthogonal-symmetric laminated beam $[0 / 90]_{\mathrm{s}}$ and unidirectional laminated beam $\left[0_{n}\right]$. The material properties of the boron/aluminum composite are listed as follows in [24]. The density $\rho=2653.0 \mathrm{~kg} / \mathrm{m}^{3}$; other material characteristic parameters are listed in Table 1. For the single material structure beam with boron aluminum alloy, the modulus of elasticity $E_{1}=215.3 \mathrm{GPa}$, the density $\rho=2766.7 \mathrm{~kg} / \mathrm{m}^{3}$, and Poisson's ratio $\mu=0.3$.

The initial parameters are the following: the displacement and velocity of the spacecraft body is zero, namely, $\mathbf{r}_{0}=0$ and $\left.\dot{\mathbf{r}}\right|_{t=0}=0$. The spacecraft body experiences a large rotation motion around a fixed axis $e_{2}$ in Figure 5, Euler parameter $\vartheta=0$ and $\varphi=0$, and the initial motion position $\left.\psi\right|_{t=0}=0$. Moreover, the initial velocity of the 


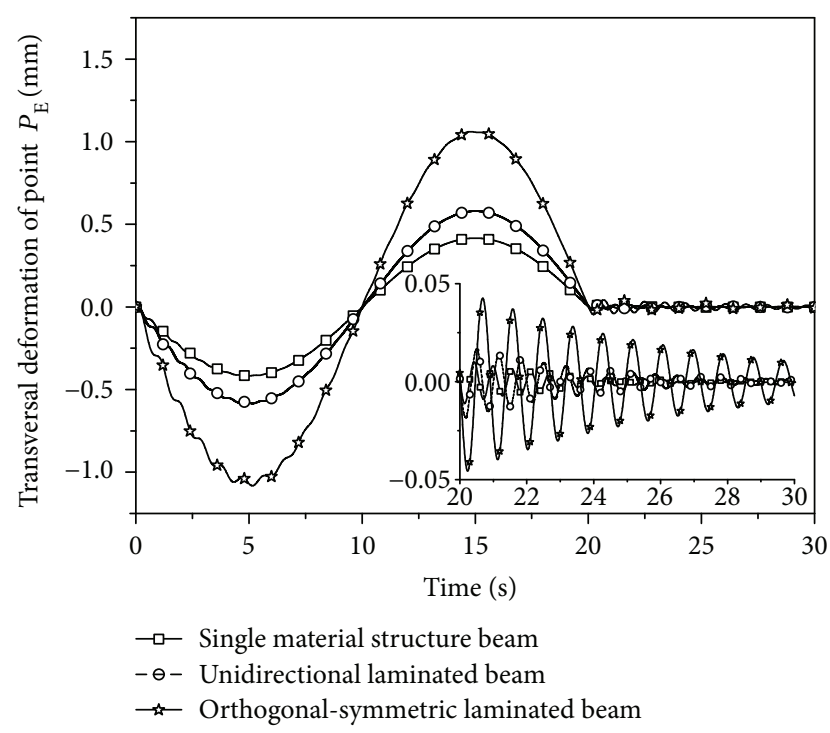

Figure 6: Transversal deformation of point $P_{\mathrm{E}}$.

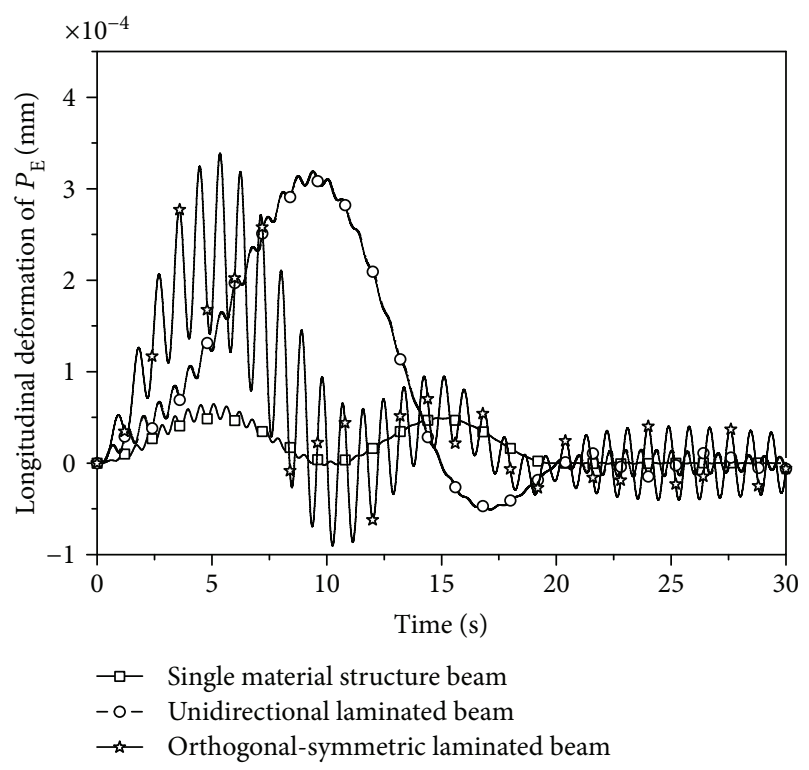

Figure 7: Longitudinal deformation of point $P_{\mathrm{E}}$.

flexible beam is assumed as zero without any external load disturbance during the motion.

To reveal the dynamics characteristics of the spacecraft beam with a large-scale motion as shown in Figure 5, the dynamic behavior of a spacecraft body composed of a rectangle beam with different material properties has been studied in this section. The transversal and longitudinal deformations of the end point $P_{\mathrm{E}}$ in the singular material beam and laminated beam are shown in Figures 6 and 7, respectively. From the two figures, when $0 \leq t \leq 20.0 \mathrm{~s}$, the deformation displacement $\mathbf{u}$ of the laminated beam has greater fluctuations for its transversal and longitudinal components. Meanwhile, because the $\mathbf{Q}$ and $\underline{\widehat{\mathbf{B}}}=\sum_{k=1}^{L} \mathbf{B}^{(k)} \boldsymbol{\Phi}$ are introduced in (37) to express the coupling stiffness matrix $\mathbf{k}_{f f}$ of the anisotropy of materials, the deformation of the laminated beam is

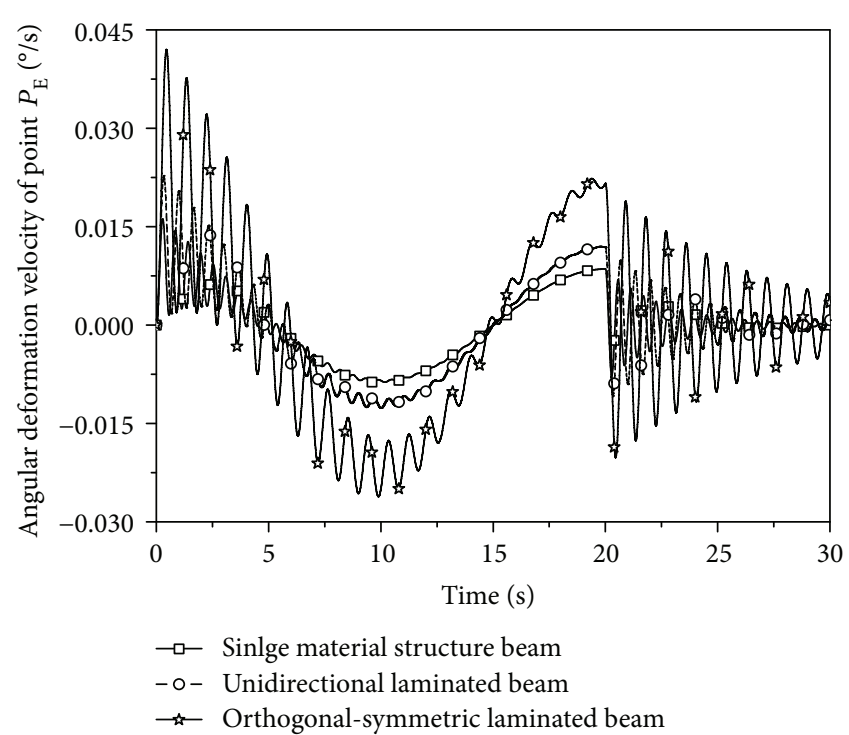

Figure 8: Angular deformation velocity of point $P_{\mathrm{E}}$.

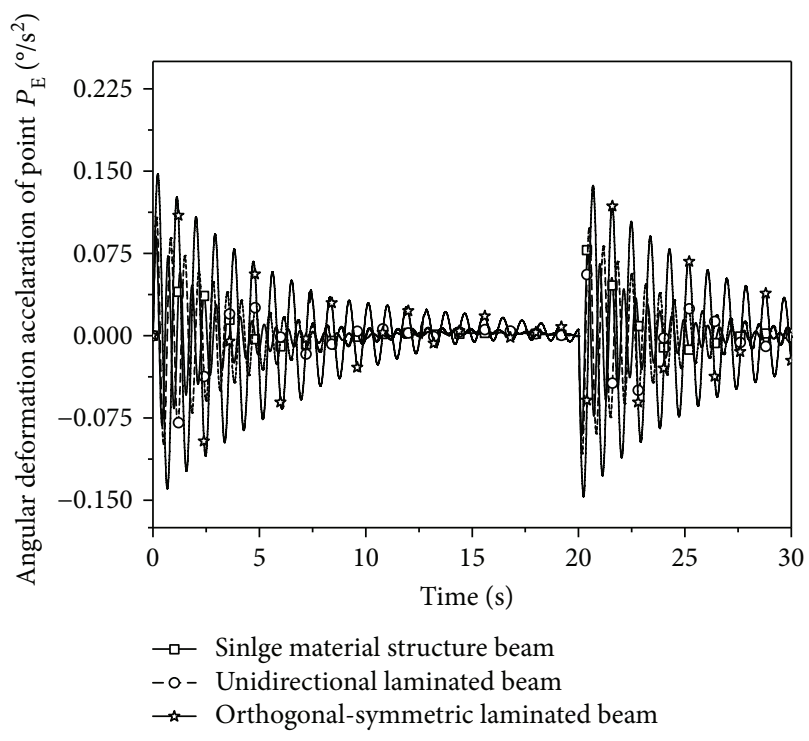

Figure 9: Angular deformation acceleration of point $P_{\mathrm{E}}$.

larger than that of the isotropic beam. Consequently, the geometric nonlinear effect of laminated structures can be described more exactly. Besides, the unidirectional laminated beam and the orthogonal symmetric beam show greater difference because the coupling stiffness matrix $\mathbf{k}_{f f}$ can produce the differences caused by the laying angle and laying layers of the laminated beam. Likewise, when $t>20.0 \mathrm{~s}$, the response of the three beams can converge to the same equilibrium position with low-amplitude decay oscillations, but the amplitude of singular material beam is smaller. Thus, it can be seen that modeling without considering the laminated composite structure will lead to greater errors and cannot exactly describe the spacecraft dynamics responses.

The angular deformation velocity and acceleration curves of point $P_{\mathrm{E}}$ of a singular material and laminated beams are illustrated in Figures 8 and 9, respectively. From the two 


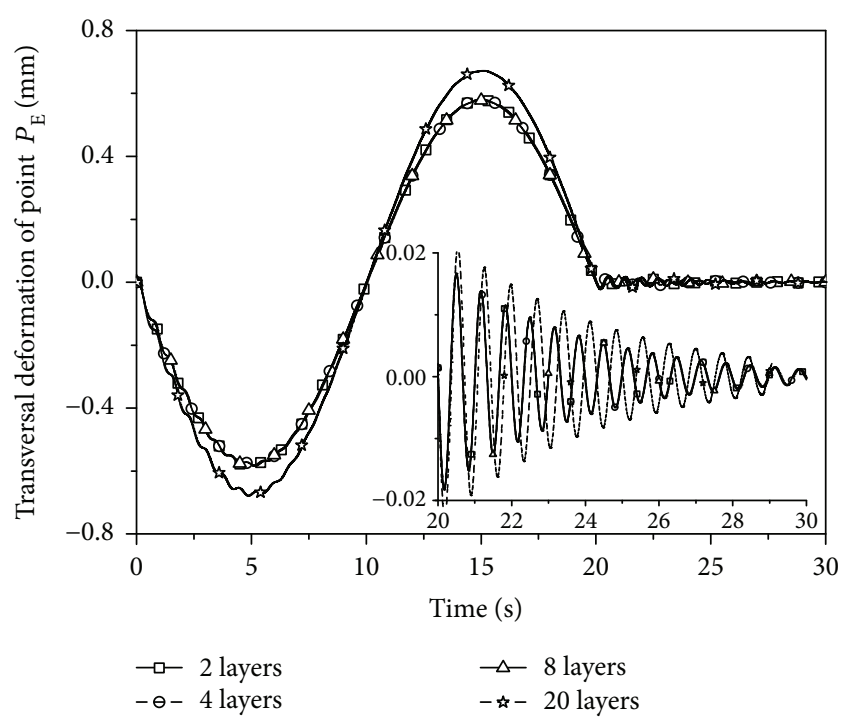

Figure 10: Transversal deformation of point $P_{\mathrm{E}}$.

figures, the variation trend of those curves is consistent between the total motions of singular material and laminated beams. The velocity of the laminated beam fluctuates obviously, so obvious vibration is induced in the motions. Meanwhile, due to persistent disturbances by the nonlinear elastic force $\mathbf{F}_{f}^{*}$ in (41), the value of angular acceleration amplitude of the laminated beam is much larger than that of the singular material beam. Furthermore, the obvious disturbing force will be induced to increase the coupling dynamics effect. Thus, it can be seen that the differences of system dynamics responses between the singular material and laminated beams are much more obvious. For this reason, the geometric nonlinear effect of laminated structures must be considered in the study of the dynamic characteristics of the spacecraft system.

Furthermore, we study the influences of different laying layers of laminated structure on the system dynamics characteristics. The structural dimensions and material parameters of the beam are defined by Figure 5 and Table 1, respectively, and the numbers of layers of the laminated beam $L$ are $2,4,8$, and 20, and laying angle of the unidirectional laminated beam $\theta$ is $0^{\circ}$.

Figures 10 and 11 show the transversal and longitudinal deformation of the unidirectional laminated beam with different layer thickness. From the two figures, when the number of laying layers $L \leq 8$ during the total motion of the laminated beam, the responses of transversal and longitudinal deformations of point $P_{\mathrm{E}}$ are similar. When $L=20$, the value of deformation of the laminated beam obviously become greater due to the coupling stiffness matrix $\mathbf{k}_{f f}$ considering the influence of laying layers $L$ in the matrix $\underline{\widehat{B}}$. Thus, as the thickness of each layer of the laminated beam increases, the differences of deformations tend to become larger.

Figures 12 and 13 show the angular deformation velocity and acceleration of point $P_{\mathrm{E}}$ with different laying layers of the laminated composite beam, respectively. From the two

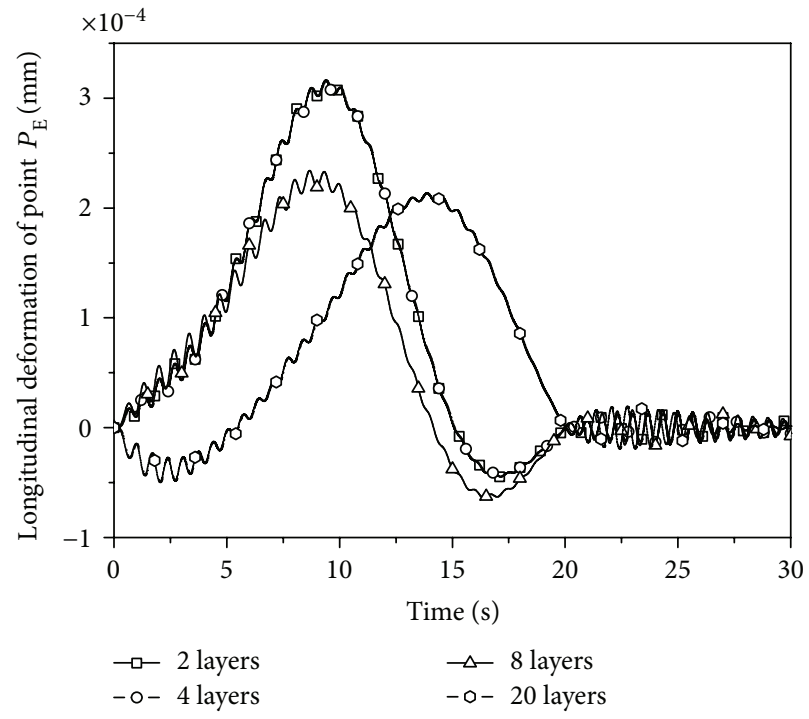

FIgUre 11: Longitudinal deformation of point $P_{\mathrm{E}}$.

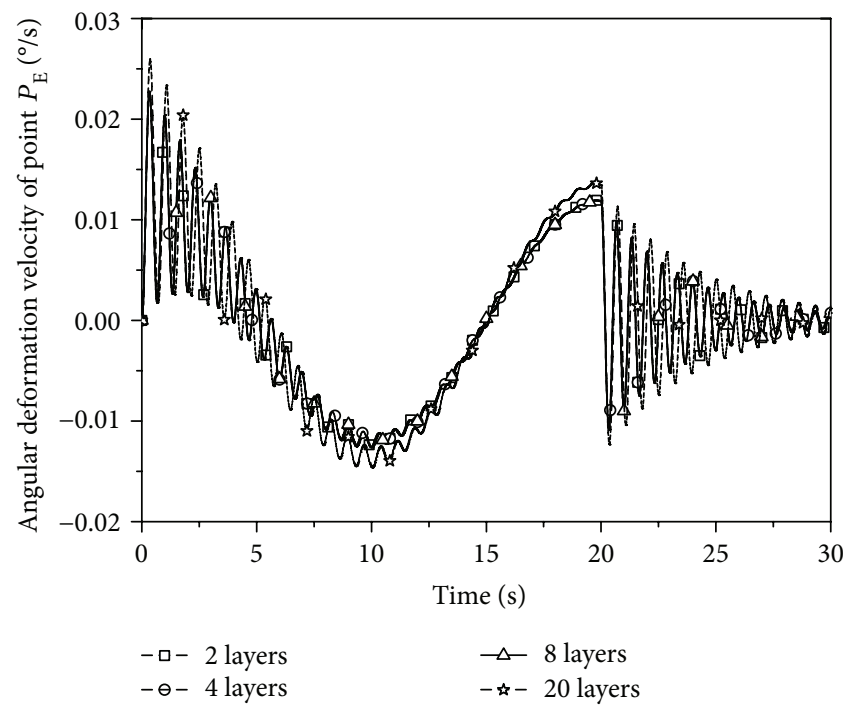

Figure 12: Angular deformation velocity of point $P_{\mathrm{E}}$.

figures, in the laminated beam model, the difference between values of angular deformation velocity and acceleration is smaller as the layers $L$ increases. However, as a whole, the vibration amplitudes tend to increase as the thickness of laying layer decreases. For this reason, the influence of thickness of laying layer should be considered carefully when a laminated beam rotates with large rotations.

The transverse and longitudinal deformation of point $P_{\mathrm{E}}$ with different laying angles $\left(0^{\circ} / 45^{\circ} / 90^{\circ}\right)$ are illustrated in Figures 14 and 15, respectively. From the two figures, for $\theta=0^{\circ}$, the elastic deformation varies between $-2.0 \mathrm{~mm}$ and $2.0 \mathrm{~mm}$, and for $\theta=90^{\circ}$, the elastic deformation varies between $-8.0 \mathrm{~mm}$ and $8.0 \mathrm{~mm}$. Accordingly, the elastic deformation of the laminated beam becomes larger as the laying angle increases. In general, the laying angles of laminated beams have significant influences on the dynamic properties of a laminated composite beam with a large-scale motion. 


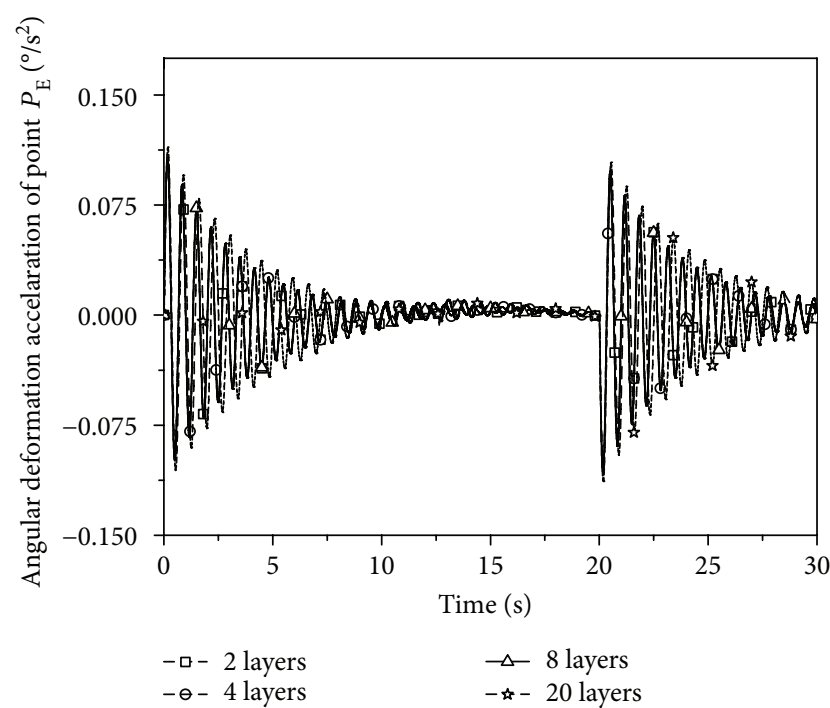

Figure 13: Angular deformation acceleration of point $P_{\mathrm{E}}$.

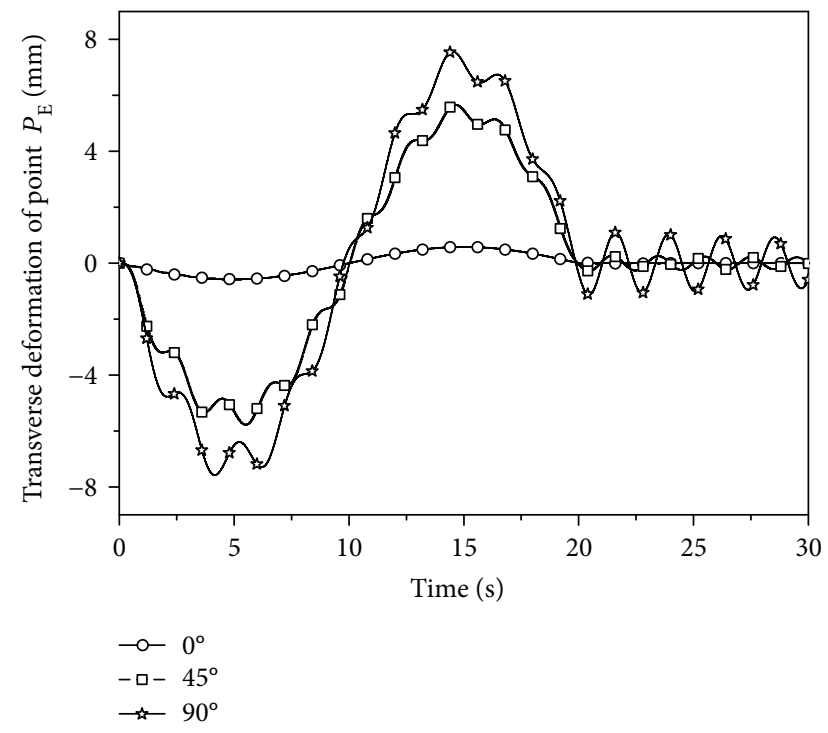

Figure 14: Transverse deformation of point $P_{\mathrm{E}}$.

Through the above analysis, the dynamics characteristics of the rectangle beam considering laminated composite material structures and simplification of isotropic material (singular material) from the conventional equivalence have been verified preliminarily by using numerical methods. And, the complete expressions of the coupling stiffness matrix and the nonlinear elastic force are considered in the dynamic modeling of the spacecraft system. The results show that the laminated structure has significant influences on the exact calculation of the dynamic model. This also reveals the importance and correctness of considering laminated composite structures. Meanwhile, the influence of the laminated composite beam with various lamination parameters on the system dynamic behavior is further carefully considered in this section. The results also show that the number of layers and the laying angles have more significant influences on system dynamics properties.

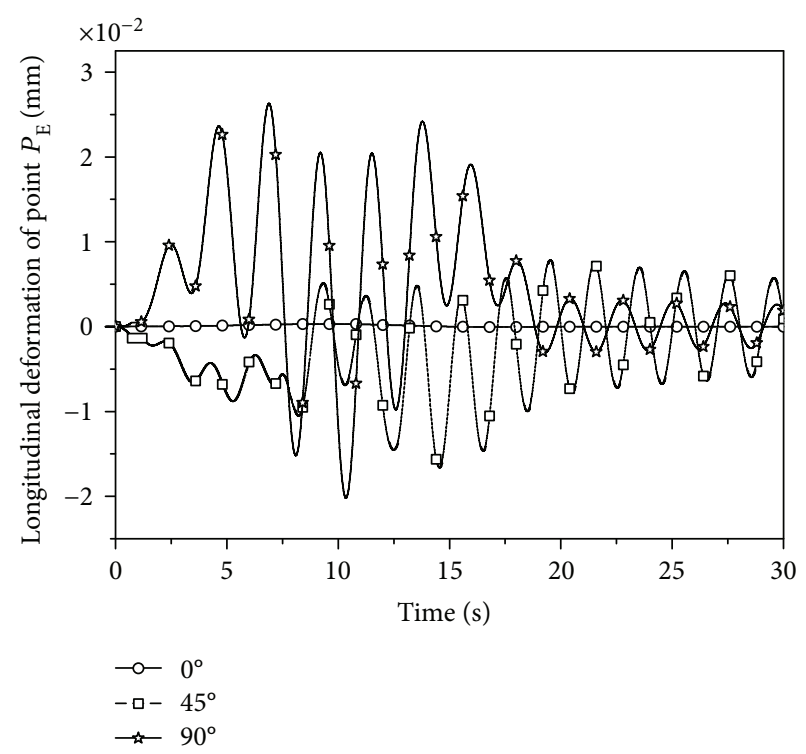

FIgURe 15: Longitudinal deformation of point $P_{\mathrm{E}}$.

\section{Conclusions}

When the spacecraft with laminated beam appendages undergoes large-scale motions, such as attitude adjustment and orbital maneuver, the elastic deformation of laminated composite appendages can be induced, which can influence the dynamics properties of the spacecraft system. From these reasons, the rigid-flexible coupling dynamic model for a spacecraft body with laminated composite beam-shape appendages have been presented in this paper by considering constitutive relationships of anisotropic laminated structures. Accordingly, the important influences of the coupling stiffness matrix and the nonlinear elastic force are considered in this model. Furthermore, the numerical simulations of laminated composite beams with a large rotation motion are conducted by considering the influences of the laminated structures and equivalent laminated beams of a singular material, different laying angles, and layers on the dynamics properties of the spacecraft system. The numerical results indicate that characteristics of material properties, the number of layers, and laying angles cannot be ignored for the dynamic analysis of large-scale rigid-flexible multibody systems with laminated composite structures.

\section{Conflicts of Interest}

The authors declare that they have no conflicts of interest.

\section{Acknowledgments}

This material is based on Projects 51575126 and 51675118 supported by the National Natural Science Foundation of China and Project 2015T80358 supported by the China Postdoctoral Science Foundation. 


\section{References}

[1] C. M. C. Roque, D. S. Fidalgo, A. J. M. Ferreira, and J. N. Reddy, "A study of a microstructure-dependent composite laminated Timoshenko beam using a modified couple stress theory and a meshless method," Composite Structures, vol. 96, pp. 532-537, 2013.

[2] J. R. Vinson and R. L. Sierakowski, The Behavior of Structures Composed of Composite Materials, Springer, Netherlands, 1986.

[3] R. K. Kapania and S. Raciti, "Recent advances in analysis of laminated beams and plates. Part I - sheareffects and buckling," AIAA Journal, vol. 27, no. 7, pp. 923-935, 1989.

[4] J. N. Reddy, "A general non-linear third-order theory of plates with moderate thickness," International Journal of Non-Linear Mechanics, vol. 25, no. 6, pp. 677-686, 1990.

[5] H. Zhang et al., "Optical and mechanical excitation thermography for impact response in basalt-carbon hybrid fiberreinforced composite laminates," IEEE Transactions on Industrial Informatics, vol. PP, no. 99, p. 1, 2017.

[6] H. Zhang, L. Yu, U. Hassler et al., "An experimental and analytical study of micro-laser line thermography on micro-sized flaws in stitched carbon fiber reinforced polymer composites," Composites Science and Technology, vol. 126, pp. 17-26, 2016.

[7] A. L. Highsmith and K. L. Reifsnider, "Stiffness-reduction mechanisms in composite laminates," in Damage in Composite Materials: Basic Mechanisms, Accumulation, Tolerance, and Characterization, pp. 103-117, ASTM International, West Conshohocken, PA, USA, 1982, STP775.

[8] M. A. Neto, J. A. C. Ambrósio, and R. P. Leal, "Composite materials in flexible multibody systems," Computer Methods in Applied Mechanics and Engineering, vol. 195, no. 50-51, pp. 6860-6873, 2006.

[9] J. Li, S. Wang, X. Li, X. Kong, and W. Wu, "Modeling the coupled bending-torsional vibrations of symmetric laminated composite beams," Archive of Applied Mechanics, vol. 85, no. 7, pp. 991-1007, 2015.

[10] L. Tian and J. Liu, "An improved dynamic model for hub and laminated composite plate system considering warping effect," Mechanics Research Communications, vol. 74, pp. 14-19, 2016.

[11] G. B. Chai and C. W. Yap, "Coupling effects in bending, buckling and free vibration of generally laminated composite beams," Composites Science and Technology, vol. 68, no. 7-8, pp. 1664-1670, 2008.

[12] X. S. He, F. Y. Deng, G. Y. Wu, and R. Wang, "Dynamic modeling of a flexible beam with large overall motion and nonlinear deformation using the finite element method," Acta Physica Sinica, vol. 59, no. 1, pp. 25-29, 2010.

[13] S. Abrate, "Impact on composite structures," Cambridge University Press, Cambridge, England, 1998.

[14] S. Sfarra, F. López, F. Sarasini et al., "Analysis of damage in hybrid composites subjected to ballistic impacts: an integrated non-destructive approach," in Handbook of Composites from Renewable Materials, V. K. Thakur, M. K. Thakur, and M. R. Kessler, Eds., pp. 175-210, John Wiley \& Sons, Inc., Hoboken, NJ, USA, 1st edition, 2017, Chapter: 8.

[15] S. B. Wu and D. G. Zhang, "Rigid-flexible coupling dynamic analysis of hub-flexible beam with large overall motion," Journal of Vibration Engineering, vol. 24, no. 1, pp. 1-7, 2011.

[16] X. S. Zhang, D. G. Zhang, and J. Z. Hong, "Rigid-flexible coupling dynamic modeling and simulation with the longitudinal deformation induced curvature effect for a rotating flexible beam under large deformation," Chinese Journal of Theoretical and Applied Mechanics, vol. 48, no. 3, pp. 692-701, 2016.

[17] G. Y. Wu, X. S. He, and F. Y. Deng, "Dynamic analysis of a rotating composite plate," Journal of Vibration and Shock, vol. 27, no. 8, pp. 149-154, 2008.

[18] K. Q. Pan and J. Y. Liu, "Rigid-flexible coupling dynamics of composite beam considering shear deformation," Journal of Shanghai Jiaotong University, vol. 43, no. 8, pp. 12931297, 2009.

[19] M. Karama, K. S. Afaq, and S. Mistou, "Mechanical behaviour of laminated composite beam by the new multi-layered laminated composite structures model with transverse shear stress continuity," International Journal of Solids and Structures, vol. 40, no. 6, pp. 1525-1546, 2003.

[20] H. H. Yoo, S. H. Lee, and S. H. Shin, "Flapwise bending vibration analysis of rotating multi-layered composite beams," Journal of Sound and Vibration, vol. 286, no. 4-5, pp. 745-761, 2005.

[21] A. Nosier and J. N. Reddy, "A study of non-linear dynamic equations of higher-order shear deformation plate theories," International Journal of Non-Linear Mechanics, vol. 26, no. 2, pp. 233-249, 1991.

[22] M. Xu and G. Q. Xu, "Finite element analysis of a laminated beam with coupled bending-torsional deflections," Journal of Nanjing University of Aeronautics \& Astronautics, vol. 19, no. 3, pp. 35-44, 1987.

[23] J. N. Reddy, Mechanics of Laminated Composite Plates and Shells: Theory and Analysis, CRC Press, Boca Raton, FL, USA, 2006.

[24] C. T. Sun and R. S. Vaidya, "Prediction of composite properties from a representative volume element," Composites Science and Technology, vol. 56, no. 2, pp. 171-179, 1996. 


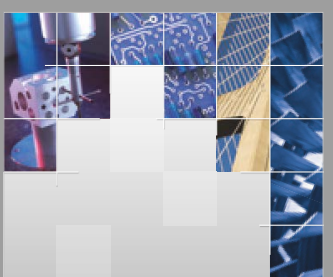

\section{Enfincering}
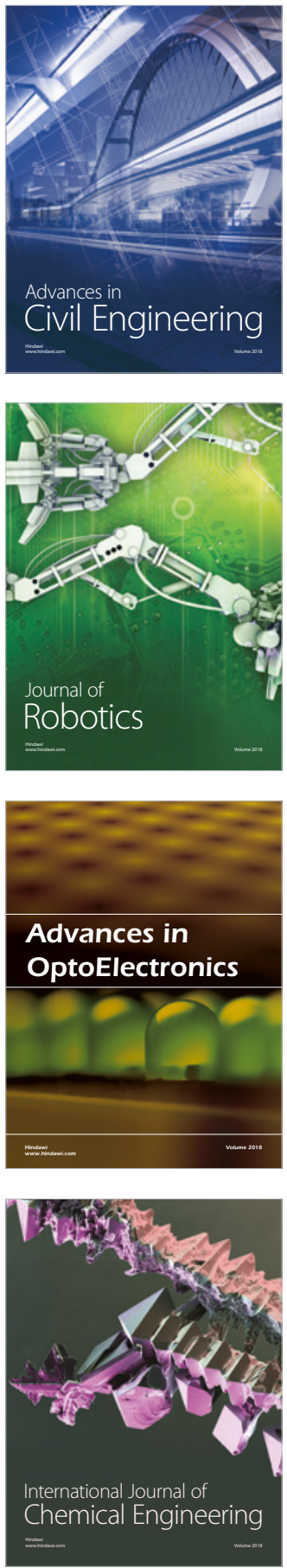

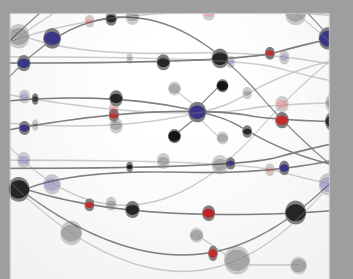

\section{Rotating \\ Machinery}

The Scientific World Journal

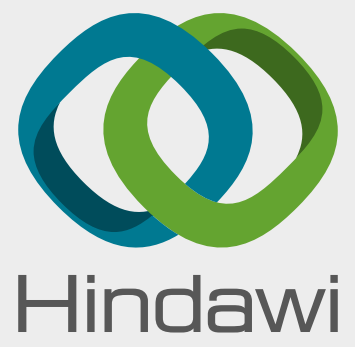

Submit your manuscripts at

www.hindawi.com
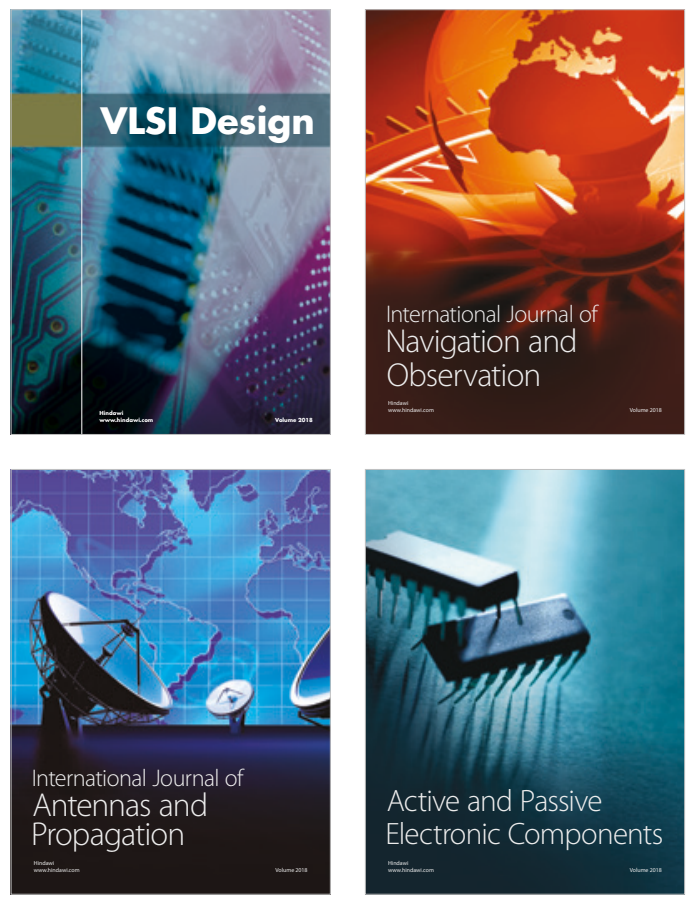
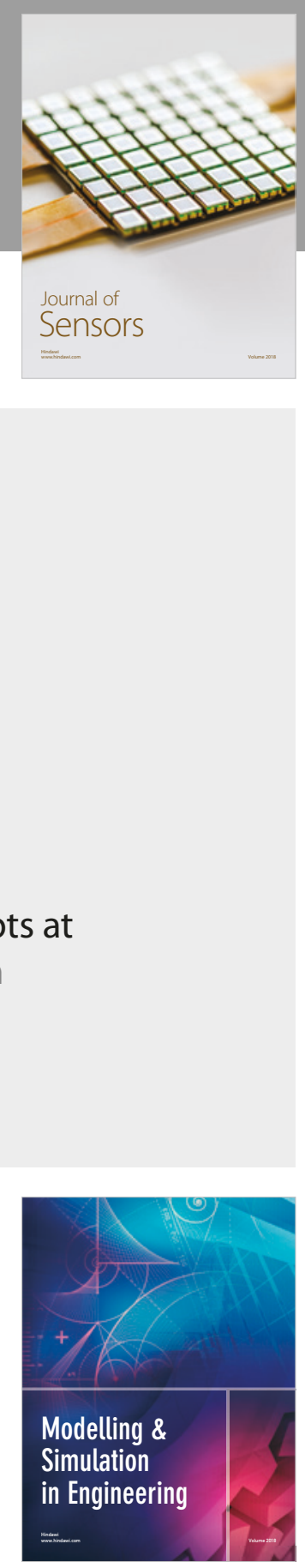

\section{Advances \\ Multimedia}
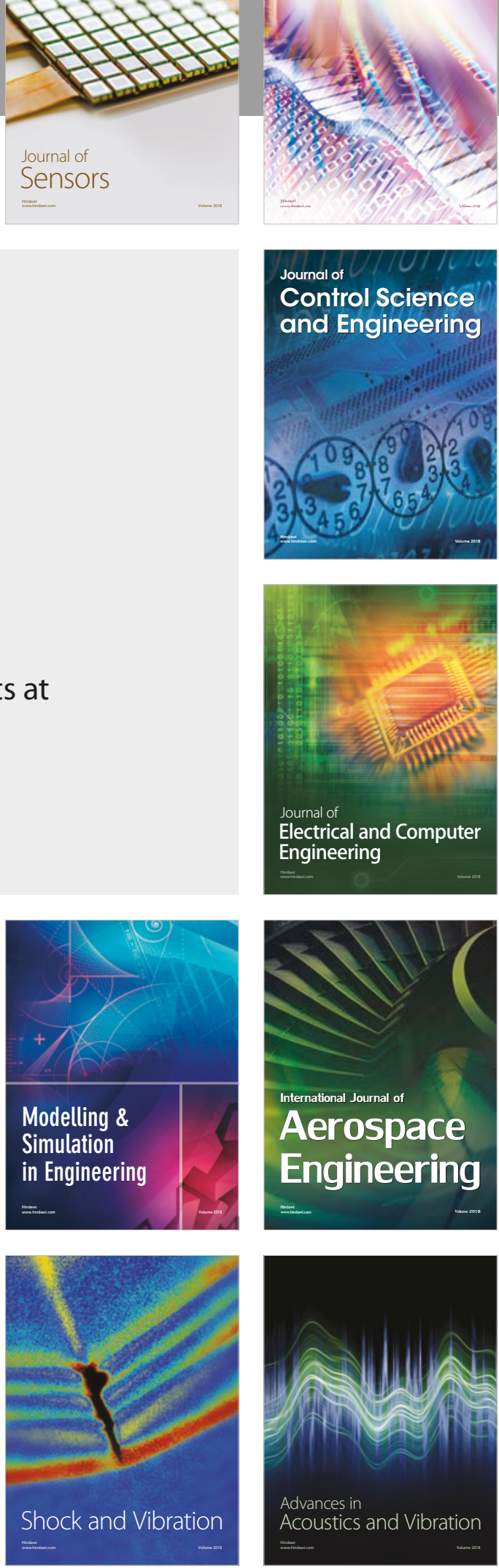